\title{
The Effect of Myrtus, Honey, Aloe vera and Pseudomonas Phage Treatment on Infected Second Degree Burns: in vivo Study
}

\author{
Soheil Khaleghverdi ${ }^{1}$, Abouzar Karimi ${ }^{2}$, Roshanak Soltani ${ }^{3}$, Reza Zare ${ }^{4, *}$ (D) \\ Department of Basic Sciences, East Tehran Branch, Islamic Azad University, Tehran, Iran \\ Microbiology laboratory, the Research section of Azmoon Salamat Iranian Co., Guilan, Iran \\ Science and Research Branch, Islamic Azad University, Tehran, Iran \\ Faculty of Chemistry, Bu-Ali Sina University, Hamadan, Iran \\ * Correspondence: rzare81@gmail.com;
}

Received: 18.05.2020; Revised: 8.06.2020; Accepted: 12.06.2020; Published: 16.06.2020

\begin{abstract}
Many researches have been exerted to find an application dressing for wound healing and also attain a considerable microbial reduction in burn wounds. In this study, the healing effect of a mixed herbal ointment (containing Myrtus, honey, Aloe vera, and pseudomonas phage) on the healing process of second degree burn wounds infected with Pseudomonas aeruginosa in comparison was evaluated. For this purpose, a hot metal square piece $(4 \times 2 \mathrm{~cm}, 50 \mathrm{~g})$ was applied using a standard burning technique, and the applied pressure on the skin kept the same for all animals, then infected with Pseudomonas aeruginosa. Rats were randomly divided into 2 groups. Group 1 was treated with mixed herbal ointment, and group 2 received no treatment (control group). The treatment was daily, and sampling was weekly for three consecutive weeks (7, 14, and 21-day). Formalin 10\% was used for tissue fixation. Wound healing in test and control groups was investigated by macroscopic and microscopic methods using Hematoxylin-Eosin staining. It wound contraction evaluation (Image J software). Macroscopic findings showed that wound contraction of the mixed herbal ointment group was significantly higher than the control group for 21 days. Hematoxylin-Eosin staining revealed that the epithelialization was considerably more completed in the mixed herbal ointment group in comparison with the control group. Also, neovascularization was significantly higher in the mixed herbal ointment group. The comparative results demonstrated that the mixed herbal ointment group had a significant difference $(\mathrm{P}<0.05)$ with a non-treated group (control). Therefore, the mixed herbal ointment is suggested as a suitable candidate for the treatment of second-degree burn wounds infected to pseudomonas aeruginosa.
\end{abstract}

Keywords: Honey; sesame oil; Pseudomonas aeruginosa; burn; wound healing.

(C) 2020 by the authors. This article is an open-access article distributed under the terms and conditions of the Creative Commons Attribution (CC BY) license (https://creativecommons.org/licenses/by/4.0/).

\section{Introduction}

Skin is the largest organ of vertebrates, is a soft tissue covering the outer surface of their body, and constitutes two layers of epiderm and derm. One may also include the subcutaneous tissue, so-called hypoderm that attaches the two upper layers to the underlying tissues such as bone and muscles. Many known compartments such as blood and lymphatic vessels, sweat glands, and hair follicles are located in the derm and hypoderm. When the dermis- the main part of the skin where hair follicles and sweat glands are located - is injured, the complex process of healing triggers automatically. Healing contains a series of certain 
phenomena during a very organized process involving several agents. For the reconstruction of the injured tissue in the wound, parenchymal and connective tissue cells should be reproduced and migrate to the right place, so it is a dynamic physiological procedure [1-4].

Wound healing is classically performed as a dynamic coordinated cascade in four overlapping steps: hemostasis (bleeding stop), inflammation, proliferation (granulation tissue formation), and regeneration (remodeling) [1, 5]. In this regard, after hemostasis, several cells contribute to the inflammatory phase, which promotes different cells' proliferation and collagen synthesis. Thereafter, the wounded tissue starts restructuring; the collagen microfibrillar and new epidermis (the outermost layer) maturates, and new fibroblasts and vessels are generated [5,6]. Some unnatural conditions such as dysregulated inflammation, superfluous free radicals, decreased angiogenesis and detracted collagen storage may detain this the normal systematized process and lead in situations like non-healing chronic wounds [7-10].

A very problematic situation is affecting the wound healing cascade burns, which is entailed with several life-quality decreasing problems (physical and psychological) as well as mortality. As an emergency and acute disorder, burn wound healing is growingly addressed in the medicinal literature trends in both developed and developing countries, including the injuries during pregnancy. At present, many studies are searching for novel dressings with more healing potential and antibacterial properties other than the silver sulfadiazine as the gold standard [11-16]. Avoiding the clinical and environmental consequences and expenses, organic and natural materials have attracted the consideration of researchers in this field. Honey can be named the earliest natural treatment for wounds, which has been highly appreciated in several old-style medication references to the extent that it was even implied in the Holy Quran more than 14 centuries ago [17-19].

In traditional medicine literature, honey has been employed for treating respiratory, urinary, gastrointestinal, and skin diseases, including ulcers, wounds, eczema, psoriasis, and dandruff. Today, it is confirmed that honey promotes healing and scar fading by raising tissue regeneration and diminishing inflammation, edema, and exudation [20]. Also, a considerable portion of present scientific studies addresses the characteristics of medicinal herbal products, which have been conventionally used for burn wound healing for centuries all over the world [21-24].

Many of these studies confirm the efficiency of medicinal plants in burn wound treatment. As an instance, the sesame oil has been studied solely or mixed (e.g., with camphor and honey) for its medication features on debridement necrotic burns [2, 25]. In the present study, a mixed herbal ointment (Myrtus, honey, Aloe vera, and pseudomonas phage) has been used to examine its healing effect on the second-degree burns in vivo infected with Pseudomonas aeruginosa in comparison with the control subjects (non-treated with herbal ointment).

\section{Materials and Methods}

\subsection{Animals.}

In this study, 12 Wistar male rats (250-300 g, 2-3 months) were randomly divided into the test and control groups, which were monitored for three weeks and sampled on days 7,14 , and 21 . They were all maintained in a sheltered standard environment $\left(20-25^{\circ} \mathrm{C}\right.$ with $65-75 \%$ humidity) under the supervision of a veterinarian. During the experiment, the rats were fed with 
usual rat chow and tap water. Each group was kept in a separate cage under 12/12 hours light/dark cycle. Studies on all two groups were performed with the same conditions.

\subsection{Burns wound model.}

The rats were anesthetized by xylazine $(10 \mathrm{mg} / \mathrm{kg})$ and ketamine hydrochloride (35 $\mathrm{mg} / \mathrm{kg}$ ). The deep second-degree burn wound was created according to Tanideh et al. using a hot plate (a metal square piece, dimensions: $4 \times 2 \mathrm{~cm}, 50 \mathrm{~g}$ ) at a fixed temperature [24]. Briefly, the dorsum skin was shaved using an electrical clipper and burned using a plate. The tool was warmed for $5 \mathrm{~min}$ in hot water and left in contact with the skin for 10 seconds with an equal pressure). Then, the second-degree burn wounds were infected with Pseudomonas aeruginosa $(1.5 \times 104 \mathrm{Cfu} / \mathrm{ml})$ by subcutaneous injection. All surgical procedures on laboratory animals, their maintenance conditions, and the following experimental procedures had been done in accordance with the Ethical Committee.

\subsection{Treatment.}

The mixed herbal ointment was prepared with Myrtus and Aloe vera $(20 \mathrm{ml})$ in mixing with $20 \mathrm{ml}$ of honey. And then, $2.5 \mathrm{ml}$ of optimum phage dilution was added, and $\mathrm{pH}$ was regulated in order to have a suitable $\mathrm{pH}$ for the skin. In the following, group 1 was treated with the mixed herbal ointment (including Myrtus, honey, Aloe vera, and pseudomonas phage). Group 2 was not treated as the control group. The treatment of burn wounds with mixed herbal ointment/Pseudomonas phage was performed daily. Photography sampling was done on days 7,14 , and 21.

\subsection{Macroscopic Observation.}

Response to the treatment was evaluated by taking photos from wound sites every day and analyzing by Image $\mathbf{J}$ software. The speed of wound contraction was evaluated by digital photography under general anesthesia at days 7,14 , and 21 of the treatment.

\subsection{Microscopic observations.}

The histologic criteria considered to determine the efficacy of treatment included: epithelization and neovascularization, as well as regeneration of fibroblasts and epidermis, angiogenesis, and the level of the collagen, inflammation, and hair follicles in the tissue sample using microscopy. For histological studies, the selected number of rats were sacrificed using chloroform containing jar. Afterward, the tissue samples from the wound area were taken and transformed onto a glass microscope slide, then were stained by Hematoxylin-Eosin staining [26-32]. Tissue sections were evaluated under light microscopes. The separation time of the remained scabs and the scar size was analyzed on the basis of the photos. All measurements of the treatment level were performed by a certain person.

\subsection{Statistical analysis.}

The treatment size was measured using Image $\mathbf{J}$ software. Non-parametric Friedman test was used to compare the mixed herbal ointment/pseudomonas phage and control groups $(\mathrm{P}<0.05)$. 


\section{Results and Discussion}

\subsection{Macroscopic analysis.}

During this study, the wound contraction showed to be more rapid in the mixed herbal ointment group rather than the control group. Wound contraction was significant in the mixed herbal ointment group on days 14 and 21 in comparison with the control group (Figure 1). Also, the mixed herbal ointment caused the scabs to fall and the wounds to heal in a shorter time compared to the control group. Treatment size evaluation was detected by Image $\mathbf{J}$ software between control and the mixed herbal ointment groups. Table 1 shows that wound contraction was considerable in the mixed herbal ointment group in comparison with the control group on days 14 and 21 .

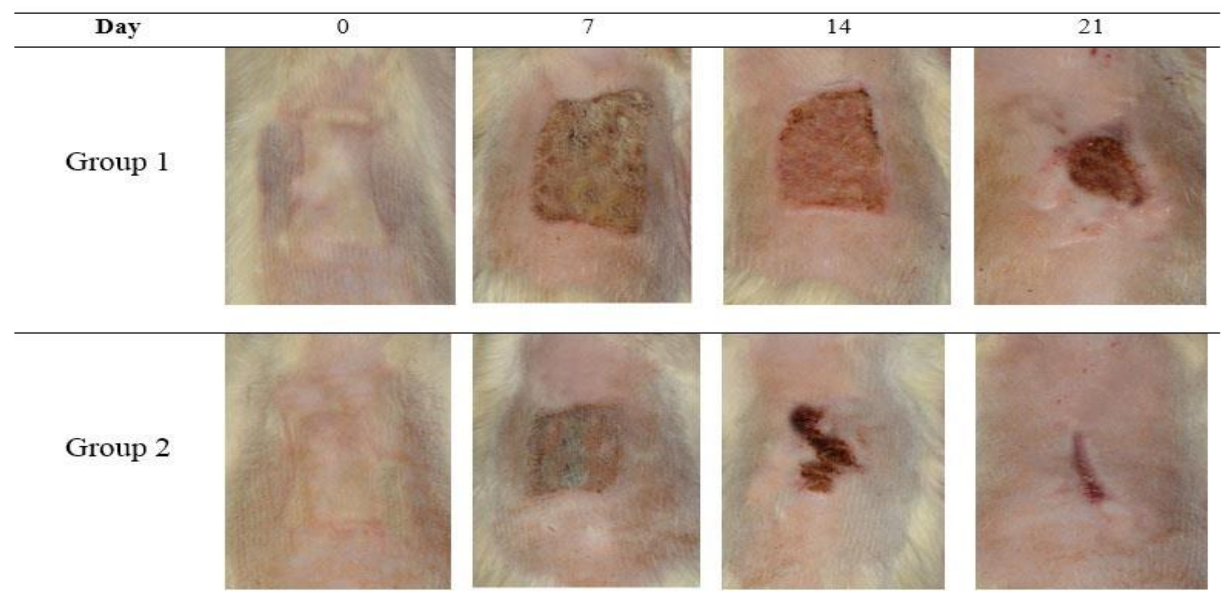

Figure 1. Macroscopic evaluation between the control and the mixed herbal ointment groups. Group 1: control, Group 2: the mixed herbal ointment.

Table 1. Treatment size evaluation between the control and mixed herbal ointment/pseudomonas phage groups.

\begin{tabular}{l|l|l|l|l} 
Day & $\mathbf{0}$ & $\mathbf{7}$ & $\mathbf{1 4}$ & $\mathbf{2 1}$ \\
\hline Group 1 & 8 & 7 & $5 / 1$ & $3 / 3$ \\
\hline Group 2 & 8 & $6 / 1$ & $2 / 3$ & $0 / 4$
\end{tabular}

*Results are based on three independent experiments. Nonparametric Friedman test, $\mathrm{P}<0.05$, Group 1: control, Group 2: the mixed herbal ointment

\begin{tabular}{|c|c|c|c|}
\hline & Day 7 & Day 14 & Day 21 \\
\hline Group 1 & & & \\
\hline Group 2 & & & \\
\hline
\end{tabular}

Figure 2. Histological Epithelization. Group 1: control, Group 2: the mixed herbal ointment (magnification $\times 40)$.

\subsection{Microscopic analysis.}

The results demonstrated a considerable epithelization in the mixed herbal ointment group on 7, 14, and 21 days in comparison with the control group. The histological 
epithelization is shown in Figure 2. In addition, neovascularization was significantly higher in the mixed herbal ointment group than the control group after 7, 14, and 21 days (Figure 3). However, in terms of wound healing, no significant difference was observed between the test and control groups (either after 7, 14, or 21 days).

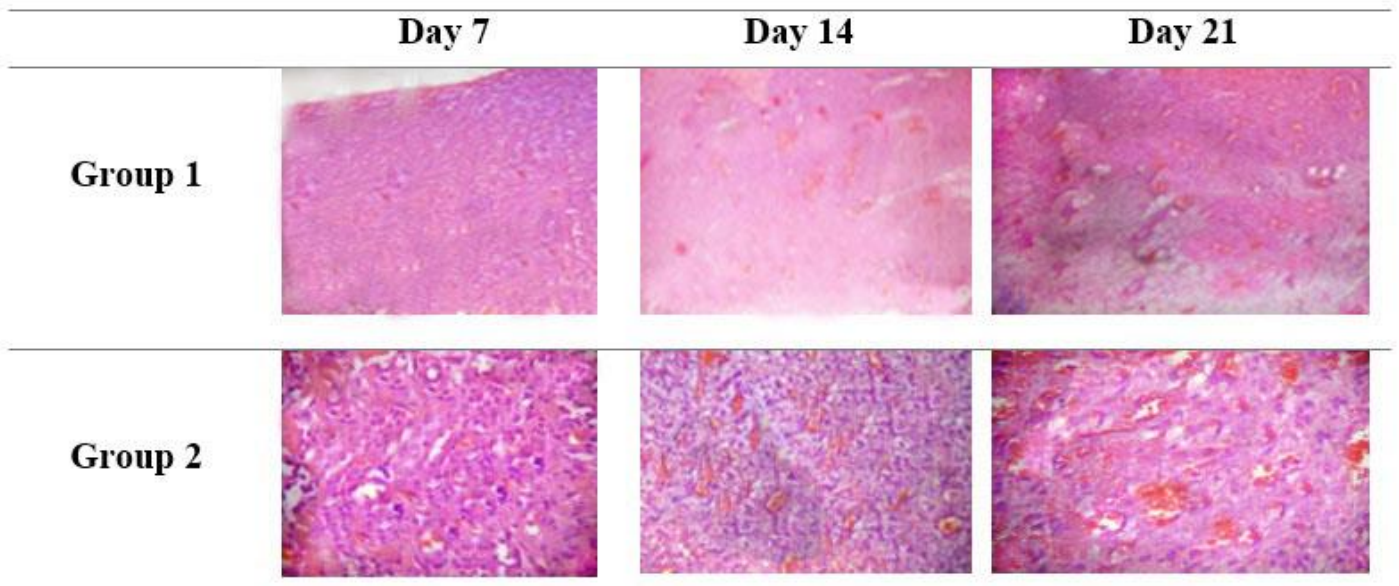

Figure 3. Histological neovascularization. Group 1: control, Group 2: the mixed herbal ointment (magnification $\times 40)$.

The results showed that the maximum peak of angiogenesis has happened on day 7. The mixed herbal ointment group had a higher angiogenesis level with a significant difference with the control group (Results obtained from three independent tests, $\mathrm{p}<0.05$ ) (Table 1). The results also show that the number of fibroblasts was significantly more increased in the mixed herbal ointment group on days 7 and 14 compared to the control group. However, no significant difference was observed on day 21 . The greatest increase in the number of fibroblasts took place on day 14. The results of microscopic studies, including the evaluating of hair follicles density, epidermis depth, collagen presence, and inflammation level (based on the existing inflammatory cells) identified a statistically significant difference between the mixed herbal ointment and control groups (Table 2). Measuring the present collagen in tissue samples showed a statistically significant increase in the mixed herbal ointment group during wound healing. The greatest growth and the presence of collagen were observed on day 21. Measuring the wound epidermis was used as an effective strategy for evaluating the amount of wound healing. After the epidermis formation, the size of the epidermis and its difference between the mixed herbal ointment and control groups were measured. Another quality criterion of wound healing is the regeneration of hair follicles. According to our results, follicular regrowth was not seen on day 7 and 14, but new hair follicles were observed on day 21 . The mixed herbal ointment and control groups consisted of an average follicle number of 3 and 8 , respectively (Results based on three independent tests, $\mathrm{p}<0.05$ ).

Table 2. Statistical comparison of fibroblasts, epidermis, blood vessels, collagen, inflammation, and hair follicles in each group on days 7, 14, and 21. Results based on the three independent and similar tests $(\mathrm{P}<0.05)$.

Group 1: control, Group 2: the mixed herbal ointment

\begin{tabular}{l|l|l|l|l|l|l|l} 
Group & Day & Epidermis & Inflammation & Hair follicle & Angiogenesis & Collagen & Fibroblasts \\
\hline \multirow{3}{*}{ Group 1 } & 7 & $10 \pm 1.36$ & $2.44 \pm 0.693$ & $0 \pm 0$ & $1.56 \pm 0.43$ & $0.58 \pm 0.002$ & $\mathbf{2 3 0 0 \pm 4 1 . 4 1}$ \\
\cline { 2 - 8 } & 14 & $25 \pm 2.12$ & $1.77 \pm 0.234$ & $0 \pm 0$ & $2.43 \pm 0.12$ & $1.15 \pm 0.51$ & $\mathbf{5 1 5 0 \pm 3 0 . 6}$ \\
\cline { 2 - 8 } & 21 & $72 \pm 2.21$ & $0.3 \pm 0.741$ & $3 \pm 0.012$ & $1.49 \pm 0.30$ & $0.87 \pm 0.002$ & $\mathbf{1 7 6 9} \pm \mathbf{1 9 . 5 5}$ \\
\hline \multirow{3}{*}{ Group 2 } & 7 & $49 \pm 1.35$ & $1.65 \pm 0.554$ & $0 \pm 0$ & $7.34 \pm 0.278$ & $2.65 \pm 0.012$ & $\mathbf{1 7 8 0 0 \pm 4 0 . 3 9}$ \\
\cline { 2 - 8 } & 14 & $141 \pm 6.00$ & $0.77 \pm 0.00043$ & $0 \pm 0$ & $6.72 \pm 0.20$ & $4.66 \pm 1.15$ & $\mathbf{3 0 1 0 0 \pm 4 9 . 3 0}$ \\
\cline { 2 - 8 } & 21 & $179 \pm 16.32$ & $0.34 \pm 0.00013$ & $7 \pm 0.2$ & $2.31 \pm 0.66$ & $5.32 \pm 0.714$ & $\mathbf{8 8 0 0 \pm 2 9 . 5 6}$
\end{tabular}


Burns are the most common injuries, specifically among children. Recoverability from burn injuries and rescue from serious health consequences depends on the cause and degree of the injury. However, more serious burns need direct emergency medical care to survive complications and death. The burn injuries are categorized into three degrees based on the seriousness, harshness, and tensity of the damage to the skin. The first-degree wounds are the least problematic, and the third-degree injuries are the most severe ones. The damages of firstdegree burns are superficial and contain red and non-blistered skin. In the second-degree burns, damages include blisters, and partial thickening of the skin extended from the beneath of epidermis into the dermis. Finally, in the third-degree burns, there is widespread thickness with a white leathery appearance $[17,19,21,33]$. Many researches are focused on investigating the effect of natural ingredients and ointments on the second-degree burn wounds. For example, Somboonwong et al. showed that aloe vera could help the wound healing promotion on the second-degree burn wound [33]. Afshar et al., also showed that the topical application of Emu oil on the II-degree burns in Balb/c mice could positively effect the wound healing and hair follicles recuperation in the margins of the wound. According to their report, the superficial application of Emu oil studied, however, has a slow healing process and causes inflammation to last longer, increases the number of hair follicles more than what can be seen in a non-treated control group. Also, Emu oil treatment led to appearing more active and mature hair follicles in several layers and increasing fibrogenesis and collagen synthesis [34].

Chen et al., compared the effect of silver nanoparticles, $1 \%$ silver sulfadiazine cream, and vaseline dressings on second degree burn wounds in patients with superficial and deep injuries. Using before and after dressing change swab bacterial cultures, they indicated that silver nanoparticle dressing could reduce the risk of wound infection and accelerate the wound healing [35]. In another study, Khorasani et al. determined that saffron (Crocus sativus) pollen extract cream can efficiently make the wound healing of hot water-induced burns faster. Their results were reported in comparison with silver sulfadiazine (SSD) on second-degree burn injuries in rat models [36]. Gupta et al., performed a retrospective review on the records of patients with first and second-degree burns admitted to their institution within 5 years. Considering several factors including the burn-dressing interval, the site, percentage, degree, and depth of burns, duration of healing, remained scar, etc. they concluded that wound sterilization was faster and wound healing increased more in the case of honey dressing [17]. Akhoondinasab et al. have compared the effects of Robaxin, Rimojen, SSD, and aloe vera on the healing process of both second and third-degree burn injuries in rat models. Digital photography assessment of histological parameters (PMN, epithelialization, fibrosis, and angiogenesis) showed that displayed a more considerable performance in wound healing. Also, aloe vera treating could ameliorate the wounds faster than SSD [37].

In this study, in order to evaluate the healing effect of mixed herbal ointment/pseudomonas phage on the second degree burn wounds, the histologic parameters including epithelization, neovascularization, regeneration of fibroblasts and epidermis, angiogenesis, and collagen synthesis, inflammation lasting, and recreating hair follicles were measured. The wounds were also infected with Pseudomonas aeruginosa in order to indicate the potential of the mixed herbal ointment treatment in wound sterilization. Based on our observations, the epithelization and neovascularization were higher in the mixed herbal ointment group rather than in the control group. Also, the present results showed a faster burn wound contraction in the mixed herbal ointment treated group compared with the control group within study duration. Additionally, fibroblasts increasing, epidermis and blood vessel 
regeneration, collagen synthesis, hair follicles recovery, and inflammatory reactions happened more and better in rat models, which were treated with mixed herbal ointment compared to those received no treatment.

\section{Conclusions}

Considering the above results, it can be concluded that mixed herbal ointment/pseudomonas phage can be suggested as a successful candidate herbal drug for healing second degree burn wounds infected with Pseudomonas aeruginosa. This conclusion is supported by the data obtained from the time of wound healing in the macroscopic evaluation and microscopic analysis.

\section{Funding}

This research received no external funding.

\section{Acknowledgments}

This research has no acknowledgment.

\section{Conflicts of Interest}

The authors declare no conflict of interest.

\section{References}

1. Boateng, J.S.; Matthews, K.H.; Stevens, H.N.; Eccleston, G.M. Wound healing dressings and drug delivery systems: a review. J Pharm Sci 2008, 97, 2892-923, https://doi.org/10.1002/jps.21210.

2. Karami, A.; Tebyanian, H.; Barkhordari, A.; Motavallian, E.; Soufdoost, R.S.; Nourani, M.R. Healing effects of ointment drug on full-thickness wound. C. R. Acad. Bulg. Sci 2019, 72, 123-129, https://doi.org/10.7546/CRABS.2019.01.16.

3. Shakeri, F.; Tebyanian, H.; Karami, A.; Babavalian, H.; Tahmasbi, M.H. Effect of Topical Phenytoin on Wound Healing. Trauma Monthly 2016, 22, e35488, https://doi.org/10.5812/traumamon.35488.

4. Esfahanizadeh, N.; Motalebi, S.; Daneshparvar, N.; Akhoundi, N.; Bonakdar, S. Morphology, proliferation, and gene expression of gingival fibroblasts on Laser-Lok, titanium, and zirconia surfaces. Lasers Med Sci 2016, 31, 863-73, https://doi.org/10.1007/s10103-016-1927-6.

5. Soufdoost, R.S.; Mosaddad, S.A.; Salari, Y.; Yazdanian, M.; Tebyanian, H.; Tahmasebi, E.; Yazdanian, A.; Karami, A.; Barkhordari, A. Surgical Suture Assembled with Tadalafil/Polycaprolactone Drug-Delivery for Vascular Stimulation Around Wound: Validated in a Preclinical Model. Biointerface Res Appl Chem 2020, 10, 6317-6327, https://doi.org/10.33263/BRIAC105.63176327.

6. Dickinson, L.E.; Gerecht, S. Engineered Biopolymeric Scaffolds for Chronic Wound Healing. Front Physiol 2016, 7, 341, https://doi.org/10.3389/fphys.2016.00341.

7. Hassani, H.; Khoshdel, A.; Sharifzadeh, S.R.; Heydari, M.F.; Alizadeh, S.; Aghideh, A.N. TNF- $\alpha$ and TGF$\beta$ level after intraoperative allogeneic red blood cell transfusion in orthopedic operation patients. Turk J Med Sci 2017, 47, 1813-1818, https://doi.org/10.3906/sag-1508-36.

8. Sharif, F.; Steenbergen, P.J.; Metz, J.R.; Champagne, D.L. Long-lasting effects of dexamethasone on immune cells and wound healing in the zebrafish. Wound Repair Regen 2015, 23, 855-65, https://doi.org/10.1111/wrr.12366.

9. Tebyanian, H.; Mirhosseiny, S.H.; Kheirkhah, B.; Hassanshahian, M.; Farhadian, H. Isolation and Identification of Mycoplasma synoviae From Suspected Ostriches by Polymerase Chain Reaction, in Kerman Province, Iran. Jundishapur J Microbiol 2014, 7, e19262, https://doi.org/10.5812/jjm.19262.

10. Heidari, M.F.; Arab, S.S.; Noroozi-Aghideh, A.; Tebyanian, H.; Latifi, A.M. Evaluation of the substitutions in 212, 342 and 215 amino acid positions in binding site of organophosphorus acid anhydrolase using the molecular docking and laboratory analysis. Bratisl Lek Listy 2019, 120, 139-143, https://doi.org/10.4149/BLL_2019_022.

11. Karami, A.; Tebyanian, H.; Goodarzi, V.; Shiri, S. Planarians: an In Vivo Model for Regenerative Medicine. Int J Stem Cells 2015, 8, 128-33, https://doi.org/10.15283/ijsc.2015.8.2.128. 
12. Khomarlou, N.; Aberoomand-Azar, P.; Lashgari, A.P.; Tebyanian, H.; Hakakian, A.; Ranjbar, R.; Ayatollahi, S.A. Essential oil composition and in vitro antibacterial activity of Chenopodium album subsp. striatum. Acta Biol Hung 2018, 69, 144-155, https://doi.org/10.1556/018.69.2018.2.4.

13. Taherian, A.; Fazilati, M.; Moghadam, A.T.; Tebyanian, H. Optimization of purification procedure for horse F(ab')2 antivenom against Androctonus crassicauda (Scorpion) venom. Trop J Pharm Res 2018, 17, 409414, https://doi.org/10.4314/tjpr.v17i3.4.

14. Babavalian, H.; Latifi, A.M.; Shokrgozar, M.A.; Bonakdar, S.; Tebyanian, H.; Shakeri, F. Cloning and expression of recombinant human platelet-derived growth factor-BB in Pichia Pink. Cell Mol Biol (Noisyle-grand) 2016, 62, 45-51, https://doi.org/10.14715/cmb/2016.62.8.8.

15. Mosaddad, S.A.; Tahmasebi, E.; Yazdanian, A.; Rezvani, M.B.; Seifalian, A.; Yazdanian, M.; Tebyanian, H. Oral microbial biofilms: an update. Eur J Clin Microbiol Infect Dis 2019, 38, 2005-2019, https://doi.org/10.1007/s10096-019-03641-9.

16. Seifi Kafshgari, H.; Yazdanian, M.; Ranjbar, R.; Tahmasebi, E.; Mirsaeed, S.R.G.; Tebyanian, H.; Ebrahimzadeh, M.A.; Goli, H.R. The effect of Citrullus colocynthis extracts on Streptococcus mutans, Candida albicans, normal gingival fibroblast and breast cancer cells. J Biol Res 2019, 92, 8201, https://doi.org/10.4081/jbr.2019.8201

17. Gupta, S.S.; Singh, O.; Bhagel, P.S.; Moses, S.; Shukla, S.; Mathur, R.K. Honey dressing versus silver sulfadiazene dressing for wound healing in burn patients: a retrospective study. J Cutan Aesthet Surg 2011, 4, 183-7, https://doi.org/10.4103/0974-2077.91249.

18. Israili, Z.H. Antimicrobial properties of honey. Am J Ther 2014, 21, 304-23, https://doi.org/10.1097/MJT.0b013e318293b09b.

19. Subrahmanyam, M. A prospective randomised clinical and histological study of superficial burn wound healing with honey and silver sulfadiazine. Burns 1998, 24, 157-61, https://doi.org/10.1016/s03054179(97)00113-7.

20. Hussein, S.Z.; Mohd Yusoff, K.; Makpol, S.; Mohd Yusof, Y.A. Gelam Honey Inhibits the Production of Proinflammatory, Mediators NO, PGE(2), TNF-alpha, and IL-6 in Carrageenan-Induced Acute Paw Edema in Rats. Evid Based Complement Alternat Med 2012, 2012, https://doi.org/10.1155/2012/109636.

21. Amini, M.; Kherad, M.; Mehrabani, D.; Azarpira, N.; Panjehshahin, M.R.; Tanideh, N. Effect of Plantago major on burn wound healing in rat. $J$ Appl Anim Res 2010, 37, 53-56, https://doi.org/10.1080/09712119.2010.9707093.

22. Noroozi-Aghideh, A.; Kheirandish, M. Human cord blood-derived viral pathogens as the potential threats to the hematopoietic stem cell transplantation safety: A mini review. World J Stem Cells 2019, 11, 73-83, https://doi.org/10.4252/wjsc.v11.i2.73.

23. Noroozi-Aghideh, A.; Kashani khatib, Z.; Naderi, M.; Dorgalaleh, A.; Yaghmaie, M.; Paryan, M.; Alizadeh, $\mathrm{S}$. Expression and $\mathrm{CpG}$ island methylation pattern of MMP-2 and MMP-9 genes in patients with congenital factor XIII deficiency and intracranial hemorrhage. Hematology 2019, 24, 601-605, https://doi.org/10.1080/16078454.2019.1654181.

24. Tanideh, N.; Rokhsari, P.; Mehrabani, D.; Mohammadi Samani, S.; Sabet Sarvestani, F.; Ashraf, M.J.; Koohi Hosseinabadi, O.; Shamsian, S.; Ahmadi, N. The Healing Effect of Licorice on Pseudomonas aeruginosa Infected Burn Wounds in Experimental Rat Model. World J Plast Surg 2014, 3, 99-106.

25. Anilakumar, K.R.; Pal, A.; Khanum, F.; Bawa, A.S. Nutritional, medicinal and industrial uses of sesame (Sesamum indicum L.) seeds-an overview. Agric conspec sci 2010, 75, 159-168.

26. Tebyanian, H.; Karami, A.; Motavallian, E.; Aslani, J.; Samadikuchaksaraei, A.; Arjmand, B.; Nourani, M.R. Histologic analyses of different concentrations of TritonX-100 and Sodium dodecyl sulfate detergent in lung decellularization. Cell Mol Biol (Noisy-le-grand) 2017, 63, 46-51, https://doi.org/10.14715/cmb/2017.63.7.8.

27. Tebyanian, H.; Karami, A.; Motavallian, E.; Samadikuchaksaraei, A.; Arjmand, B.; Nourani, M.R. Rat lung decellularization using chemical detergents for lung tissue engineering. Biotech Histochem 2019, 94, 214222, https://doi.org/10.1080/10520295.2018.1544376.

28. Tebyanian, H.; Karami, A.; Motavallian, E.; Aslani, J.; Samadikuchaksaraei, A.; Arjmand, B.; Nourani, M.R. A Comparative Study of Rat Lung Decellularization by Chemical Detergents for Lung Tissue Engineering. Open Access Maced J Med Sci 2017, 5, 859-865, https://doi.org/10.3889/oamjms.2017.179.

29. Soufdoost, R.S.; Yazdanian, M.; Tahmasebi, E.; Yazdanian, A.; Tebyanian, H.; Karami, A.; Nourani, M.R.; Panahi, Y. In vitro and in vivo evaluation of novel Tadalafil/ $\beta$-TCP/Collagen scaffold for bone regeneration: A rabbit critical-size calvarial defect study. Biocybern Biomed Eng 2019, 39, 789-796, https://doi.org/10.1016/j.bbe.2019.07.003.

30. Esfahanizadeh, N.; Daneshparvar, P.; Takzaree, N.; Rezvan, M.; Daneshparvar, N. Histologic Evaluation of the Bone Regeneration Capacities of Bio-Oss and MinerOss X in Rabbit Calvarial Defects. Int J Periodontics Restorative Dent 2019, 39, e219-e227, https://doi.org/10.11607/prd.4181.

31. Esfahanizadeh, N.; Yousefi, H. Successful Implant Placement in a Case of Florid Cemento-Osseous Dysplasia: A Case Report and Literature Review. J Oral Implantol 2018, 44, 275-279, https://doi.org/10.1563/aaid-joi-D-17-00140. 
32. Daneshparvar, H.; Sadat-Shirazi, M.S.; Fekri, M.; Khalifeh, S.; Ziaie, A.; Esfahanizadeh, N.; Vousooghi, N.; Zarrindast, M.R. NMDA receptor subunits change in the prefrontal cortex of pure-opioid and multi-drug abusers: a post-mortem study. Eur Arch Psychiatry Clin Neurosci 2019, 269, 309-315, https://doi.org/10.1007/s00406-018-0900-8.

33. Somboonwong, J.; Thanamittramanee, S.; Jariyapongskul, A.; Patumraj, S. Therapeutic effects of Aloe vera on cutaneous microcirculation and wound healing in second degree burn model in rats. J Med Assoc Thai 2000, $83,417-25$.

34. Afshar, M.; Ghaderi, R.; Zardast, M.; Delshad, P. Effects of Topical Emu Oil on Burn Wounds in the Skin of Balb/c Mice. Dermatol Res Pract 2016, 2016, 6419216, https://doi.org/10.1155/2016/6419216.

35. Chen, J.; Han, C.M.; Lin, X.W.; Tang, Z.J.; Su, S.J. [Effect of silver nanoparticle dressing on second degree burn wound]. Zhonghua Wai Ke Za Zhi 2006, 44, 50-2.

36. Khorasani, G.; Hosseinimehr, S.J.; Zamani, P.; Ghasemi, M.; Ahmadi, A. The effect of saffron (Crocus sativus) extract for healing of second-degree burn wounds in rats. Keio J Med 2008, 57, 190-5, https://doi.org/10.2302/kjm.57.190.

37. Akhoondinasab, M.R.; Akhoondinasab, M.; Saberi, M. Comparison of healing effect of aloe vera extract and silver sulfadiazine in burn injuries in experimental rat model. World J Plast Surg 2014, 3, 29-34. 